Published in final edited form as:

Arch Gen Psychiatry. 2012 October ; 69(10): 993-1002. doi:10.1001/archgenpsychiatry.2012.476.

\title{
Alterations in default mode network connectivity during pain processing in borderline personality disorder
}

\author{
Rosemarie C. Kluetsch, MSc\#, \\ Central Institute of Mental Health, Medical Faculty Mannheim/Heidelberg and Department of \\ Psychiatry, Schulich School of Medicine and Dentistry, The University of Western Ontario, \\ London, Ontario, Canada
}

Christian Schmahl, MD\#, Department of Psychosomatic Medicine and Psychotherapy, Central Institute of Mental Health, Mannheim, Germany

Inga Niedtfeld, MSc, Department of Psychosomatic Medicine and Psychotherapy, Central Institute of Mental Health, Mannheim, Germany

\section{Maria Densmore, BSc,}

Department of Psychiatry, Schulich School of Medicine and Dentistry, The University of Western Ontario, London, Ontario, Canada

\section{Vince D. Calhoun, PhD,}

The Mind Research Network and Departments of Psychiatry, Electrical and Computer Engineering (Primary), Neurosciences, and Computer Science, University of New Mexico, Albuquerque, New Mexico

Judith Daniels, PhD, Department of Psychiatry and Psychotherapy, Charité Universitätsmedizin Berlin, Berlin, Germany

\section{Anja Kraus, PhD,}

Department of Psychosomatic Medicine and Psychotherapy, Central Institute of Mental Health, Mannheim, Germany

\section{Petra Ludaescher, PhD,}

Department of Psychosomatic Medicine and Psychotherapy, Central Institute of Mental Health, Mannheim, Germany

Martin Bohus, MD, and Department of Psychosomatic Medicine and Psychotherapy, Central Institute of Mental Health, Mannheim, Germany

Ruth A. Lanius, MD, PhD

Contents from this paper was presented at the $26^{\text {th }}$ Annual Meeting of the International Society for Traumatic Stress Studies (ISTSS); November 4-6, 2010; Le Centre Sheraton Montreal Hotel, Montreal, Quebec, Canada. 
Department of Psychiatry, Schulich School of Medicine and Dentistry, The University of Western

Ontario, London, Ontario, Canada

\# These authors contributed equally to this work.

\section{Abstract}

Context-Recent neuroimaging studies have associated activity in the default mode network (DMN) with self-referential and pain processing, both of which are altered in borderline personality disorder (BPD). In patients with BPD, antinociception has been linked to altered activity in brain regions involved in the cognitive and affective evaluation of pain. Findings in healthy subjects indicate that painful stimulation leads to blood oxygenation level-dependent (BOLD) signal decreases and changes in the functional architecture of the DMN.

Objective-To connect the previously separate research areas of DMN connectivity and altered pain perception in BPD and explore DMN connectivity during pain processing in patients with BPD.

Design-Case-control study

Setting-A university hospital

Participants-Twenty-five women with BPD, 92 percent with a history of self-harm, and 22 age-matched controls.

Interventions-Psychophysical assessment and functional MRI (fMRI) during painful heat versus neutral temperature stimulation.

Main Outcome Measure-DMN connectivity as assessed via independent component analysis and psychophysiological interaction analysis.

Results-Compared to controls, patients with BPD showed less integration of the left retrosplenial cortex and left superior frontal gyrus into the DMN. Higher BPD symptom severity and trait dissociation were associated with an attenuated signal decrease of the DMN in response to painful stimulation. During "pain" versus "neutral", BPD patients exhibited less posterior cingulate cortex seed region connectivity with the left dorsolateral prefrontal cortex.

Conclusion-Patients with BPD showed significant alterations in DMN connectivity, with differences in spatial integrity and temporal characteristics. These alterations may reflect a different cognitive and affective appraisal of pain as less self-relevant and aversive, and a deficiency in the switching between baseline and task-related processing. This deficiency may be related to everyday difficulties of BPD patients to regulate their emotions, focus mindfully on one task at a time, and efficiently shift their attention from one task to another.

\section{Background}

Patients with borderline personality disorder (BPD) frequently experience stress-induced aversive states of inner tension and dissociation, ${ }^{1,2}$ which are often associated with analgesia and self-injurious behavior (SIB). ${ }^{3,4}$ Specifically, many patients with BPD engage in SIB to regulate affect, decrease dissociation and regain awareness of physical sensations. ${ }^{5-7}$ Experimental studies confirm reduced pain sensitivity in patients with BPD under stress and 
non-stress conditions, which cannot be explained by sensory-discriminative or attentional factors. ${ }^{8-10}$ Instead, findings from pain research using a thermal stimulation paradigm suggest that BPD patients show altered activity in brain regions implicated in the cognitive and affective evaluation of pain. ${ }^{11,12}$ Compared to healthy controls (HC), BPD patients displayed increased activation in the dorsolateral prefrontal cortex (DLPFC) coupled with deactivation in the anterior cingulate cortex (ACC) and the amygdala in response to heat stimuli individually adjusted for equal subjective painfulness. ${ }^{11}$ Beyond pain processing, patients with BPD have shown altered metabolic activity of prefrontal and limbic brain regions during rest and in the contexts of emotion regulation and inhibitory control. ${ }^{13-15}$ Taken together, painful stimulation may play an important role in self-regulatory mechanisms in BPD, e.g. in the context of self-injury. ${ }^{7}$

The so-called default mode network (DMN) has recently been studied in the contexts of both self-referential and pain processing. ${ }^{16-19}$ The DMN comprises the medial prefrontal cortex (mPFC), posterior cingulate/retrosplenial cortex (PCC/RSC) including the precuneus $(\operatorname{PrC})$, inferior parietal lobule, lateral temporal cortex, and hippocampal formation. ${ }^{20-22}$ Activity within the DMN has been observed when individuals are at rest or engaged in stimulus-unrelated thought - presumably facilitating a state of readiness to respond to environmental changes..$^{20,23,24,25}$ Accumulating evidence suggests that the DMN comprises at least two interacting subsystems, the mPFC network and the PCC network, that serve specific, dissociable functions and may differentially modulate activity in so-called taskpositive networks. ${ }^{26-29}$

Here, we were particularly interested in the interactions between the core nodes of the DMN, the PCC and the mPFC, with other brain regions during the perception of pain. ${ }^{30,31}$ Findings in healthy subjects indicate that painful stimulation leads to BOLD signal decreases and changes in brain regions known to be part of the functional architecture of the DMN. ${ }^{19,32-34}$ Painful electrical stimulation, for example, led to a significant recruitment of areas associated with cognitive and affective pain modulation, such as the ACC and middle frontal gyrus, into the DMN. ${ }^{19,35}$ However, the relationship between DMN connectivity and pain requires further investigation, especially regarding conditions of altered pain perception as observed in BPD. Therefore, the aforementioned lines of research are brought together.

While the DMN itself may not necessarily play a central role in pain processing in healthy subjects, probing its dynamic interactions and integrated performance with other brain regions may broaden our understanding of the neural substrates underlying reduced pain perception in BPD. ${ }^{38,39}$ To date, there is only one study ${ }^{36}$ that has explicitly investigated DMN connectivity in BPD. In this study, BPD patients showed increased DMN connectivity during rest with the left DLPFC and the left insula as well as decreased connectivity with the left cuneus compared to HC. In the present study, we re-analyzed our previously published data, ${ }^{12}$ using independent component analysis (ICA) and psychophysiological interaction (PPI) analysis, to investigate changes in DMN connectivity associated with the transition from a neutral temperature (considered to be a baseline condition for the present study) to painful thermal stimulation in BPD patients and HC. 
Considering that BPD patients have previously demonstrated altered DMN connectivity with the DLPFC, cuneus and insula during rest, ${ }^{36}$ as well as abnormal recruitment of prefrontal and limbic brain regions, such as the ACC and amygdala, in the contexts of emotion ${ }^{14,15}$ and pain processing, ${ }^{11}$ we hypothesized that these brain regions would be differentially connected with the DMN in BPD patients. Consistent with previous findings, ${ }^{19,32}$ we also hypothesized that both groups would exhibit pain-related changes in connectivity with the two DMN nodes, particularly revealing a BOLD signal decrease and an increased recruitment of areas belonging to the "pain network". 30,31

\section{Methods}

\section{Participants}

Twenty-five women with BPD, 92 percent of whom had a history of SIB, and 22 healthy age-matched women were included in our study. We have previously reported on this group of subjects in a study examining the neural correlates of antinociception in BPD. ${ }^{12}$ Axis I and II diagnoses were assessed by a trained psychologist using the Structured Clinical Interview for DSM-IV Axis I Disorders (SCID-I $)^{37}$ and the International Personality Disorder Examination (IPDE). ${ }^{38}$ Trait dissociation was assessed in both groups with the German adaptation of the Dissociative Experience Scale (FDS). ${ }^{39}$ The Dissociative States Scale (DSS) ${ }^{40}$ was used to measure state dissociation and aversive inner tension immediately before and after scanning. BPD symptom severity was assessed with the Borderline Symptom List (BSL) $)^{41,42}$ and the number of DSM-IV criteria. Demographic and psychometric data are shown in Table 1.

All participants were right-handed and free of psychotropic and pain medications for at least two weeks prior to scanning. Exclusion criteria comprised a history of head trauma, chronic pain, serious medical or neurological illness, current major depression, alcohol or substance abuse or dependence in the last six months, lifetime bipolar disorder, schizophrenia, and pain disorders. Controls were excluded if they had a lifetime diagnosis of BPD as assessed by the IPDE or a current axis I diagnosis as assessed by the SCID-I.

Subjects provided written informed consent for the experimental procedures, which were approved by the ethics committee of the University of Heidelberg, Germany.

\section{Stimulus Material and Procedure}

All participants underwent psychophysical assessment and functional magnetic resonance imaging (fMRI) during heat stimulation versus neutral temperature in a block design. Heat stimuli were applied to the back of the right hand using the thermal sensory analyzer (TSAII; Medoc Advanced Medical Systems, Ramat Yishai, Israel).

Psychophysical Assessment-We used the same methods described in detail in our previous studies to characterize pain sensitivity. ${ }^{11,12}$ Here, we focused on the stimulation with a temperature individually adjusted to a subjective pain intensity rating of 40 on a numeric rating scale (NRS) from 0 (no pain at all) to 100 (worst imaginable pain). 
Functional Imaging-The second part of the experiment was performed on a 1.5-T magnetic resonance scanner equipped with a Vision gradient system and a circularly polarized head coil (Siemens Medical Solution, Erlangen, Germany). Scanning parameters and preprocessing procedures were previously described. ${ }^{11,12}$ As reported, five stimulation blocks with the individually adjusted temperature were applied. Each block lasted 30 seconds and was followed by 60 -second intervals of neutral temperature $\left(35^{\circ} \mathrm{C}\right.$, baseline). After each stimulation block, subjects rated their average pain intensity for that block using the NRS. To account for the change in temperature between neutral and pain blocks (rising and falling rates: $2^{\circ} \mathrm{C}$ per second), we removed the volumes "in between" and concatenated the ones that were acquired during stimulation with the target temperatures.

\section{Image Analysis}

Independent Component Analysis (ICA)—Group spatial ICA was conducted for all 47 subjects using the infomax algorithm ${ }^{43}$ within the GIFT software (http:// icatb.sourceforge.net/, version 1.3h). A detailed review of group ICA fMRI analyses can be found in Calhoun et al. ${ }^{44,45}$ In this study, the optimal number of independent components was found to be 29 using modified minimum description length criteria. ${ }^{46}$ We launched the ICASSO algorithm, ${ }^{47}$ implemented in GIFT, to increase the robustness of our independent components to initial algorithm conditions by repeating the ICA estimation 20 times. Single subject spatial maps and corresponding time courses were then computed (back-

reconstructed) and converted to z-scores for display and use in subsequent statistical analyses. Each voxel in the brain has a z-score representing the strength of its contribution to the component's time course..$^{48,49}$

Component Identification: The components related to the DMN were selected following visual inspection and methods previously described. ${ }^{50-52}$ Details on the selection steps can be found in the supplementary online material.

Statistical Comparison of Images: For the selected components, the individual subject maps were entered into second-level analyses in SPM8 (http://www.fil.ion.ucl.ac.uk/spm/), according to previous publications. ${ }^{52,53}$ For details, see the supplementary online material. Given the novelty of our approach and the lack of previous studies examining DMN connectivity during pain in BPD, the results of these analyses are reported at a statistical height threshold of $p<0.005$ (uncorrected) at the voxel-level. Additionally, to correct for multiple comparisons across the whole brain, we used a cluster extent correction procedure to compute the number of expected voxels per cluster according to random field theory. ${ }^{54}$ Thus, only clusters exceeding the respective number of voxels are presented. ${ }^{59-60,61} \mathrm{To}$ control for differences in subjective pain intensity during the fMRI acquisition, we entered each subject's average rating for the five "pain" blocks as a covariate of no interest into the two-sample t-tests comparing the component images of BPD patients and HC.

Statistical Comparison of Time Courses: Following methods previously described, ${ }^{45,5556}$ multiple regression analysis, using the temporal sorting function in GIFT, was performed on the ICA time courses with the SPM8 design matrix. Details can be found in the supplementary online material. This procedure resulted in a set of beta-weights that were 
entered into second-level analyses in SPSS for Windows (Rel. 18.0.0. 2009. Chicago: SPSS Inc.) to draw inferences about the degree of task-relatedness $(\mathrm{p}<0.05) .{ }^{55,57,62}$

Correlation of Time Courses with symptom severity: Using Pearson correlation analysis, we also determined the relationship between DMN component time courses and patients' average BSL, DSS and FDS scores ( $p<0.05$, Bonferroni-corrected).

Psychophysiological Interaction (PPI) Analysis-Psychophysiological interaction (PPI) analysis is a hypothesis-driven approach to study context-specific changes in effective connectivity between one or more a priori defined brain regions of interest and the rest of the brain. ${ }^{58}$ This is achieved by comparing connectivity in one context (in this case, "pain") with connectivity in another context (here, "neutral").

Using the PPI analysis methodology implemented in SPM8, we examined whether the PCC and $\mathrm{mPFC}^{26}$ were differentially connected to other brain regions with respect to each other and to the experimental context of painful versus non-painful stimulation. For each subject, an average BOLD signal time course was extracted from the two seed regions, defined as a 10-mm sphere around coordinates derived from previous studies of the DMN. ${ }^{27,59}$ The PCC analysis was centered at Montreal Neurological Institute (MNI) coordinates 0, -57, 30 and the mPFC analysis at $0,51,0$. Each PPI analysis was conducted individually for each subject and the two seed regions, focusing on two complementary contrasts, namely "neutral" greater "pain" and "pain" greater "neutral".

Group Comparison: The resulting contrast images were entered into second-level withinand between-group analyses, using one- and two-sample t-tests, respectively. PPI results are reported at a statistical height threshold of $\mathrm{p}<0.005$ (uncorrected) at the voxel-level, in addition to the cluster-extent correction described above. ${ }^{54} \mathrm{We}$ additionally performed region-of-interest analyses for those brain regions that had previously shown altered connectivity with the DMN in patients with BPD, namely the DLPFC, insula and cuneus. ${ }^{36}$ To identify whether these regions, showed a different pain-related coupling with the two seed regions in BPD patients compared to HC, we applied a more liberal height threshold of $\mathrm{p}<0.01$ (uncorrected). Correction for multiple comparisons was carried out using a small volume correction for these ROIs ( $\mathrm{p}<0.05$, SVC-corrected). ${ }^{60,67}$ To control for differences in subjective pain intensity, we entered each subject's average rating for the five "pain" blocks as a covariate of no interest into the two-sample t-tests for "pain" greater "neutral".

\section{Results}

\section{Psychophysics}

The two groups differed significantly in overall pain ratings when stimulated with different temperatures from $40^{\circ} \mathrm{C}$ to $48^{\circ} \mathrm{C}$ [analysis of variance for repeated measurements, main effect group: $F(1,45)=10.05, p=0.003]$. The mean \pm standard deviation (SD) individual temperatures derived from the psychophysical evaluation were significantly different between patients $\left(45.86^{\circ} \mathrm{C} \pm 1.31^{\circ} \mathrm{C}\right)$ and controls $\left(44.60^{\circ} \mathrm{C} \pm 1.22^{\circ} \mathrm{C}\right)[\mathrm{t}(45)=-3.40, \mathrm{p}=$. 001]. During fMRI, the two groups also differed significantly in their mean \pm SD pain 
intensity ratings for the individually adjusted temperature [patients: $47.3 \pm 13.78$, controls: $63.93 \pm 19.0 ; \mathrm{t}(45)=3.464, \mathrm{p}=0.001]$.

\section{Independent Component Analysis}

Component Identification-The selection process revealed three components that closely resembled our DMN mask and included brain areas previously implicated in the network ${ }^{20}$ : Component $28(\mathrm{r}=0.55)$, component $13(\mathrm{r}=0.43)$, and component $27(\mathrm{r}=0.29)$ (Figure 1 and eTable 1). Component 28 included mainly the PCC/RSC/PrC, lateral parietal areas and superior/middle temporal gyri, but also smaller clusters within the $\mathrm{mPFC}$, superior/middle frontal gyrus, insula and cerebellum ("posterior DMN"). Contributions of posterior DMN regions were also dominant in component 13, which included the PrC and a large cluster extending from the PCC along the cingulate gyrus. Component 27 received its strongest contributions from the mPFC and surrounding frontal areas ("anterior DMN"). The $\mathrm{PCC} / \mathrm{RSC} / \mathrm{PrC}$ and lateral parietal regions were also present, but to a lesser degree than in the other two components. Visual inspection confirmed that the same brain regions were included in the three selected components in both groups (eTable 2 and eTable 3 ).

Statistical Comparison of Images—Despite these similarities, two-sample t-tests yielded significant group differences in the integration of the left retrosplenial cortex (RSC) $[-12,-39,3 ; \mathrm{t}(44)=4.16]$ into component 28 and of the right inferior temporal gyrus (ITG) $[60,-9,-33 ; \mathrm{t}(44)=3.79]$ and left superior frontal gyrus $(\mathrm{SFG})[-21,30,51 ; \mathrm{t}(44)=3.40]$ into component 27. For those brain regions, patients showed less integration, i.e. decreased connectivity strength with other DMN areas, ${ }^{52}$ than HC (Figure 2). We did not find significant group differences in the connectivity of component 13 .

Statistical Comparison of Time Courses-Temporal correlation analysis revealed that only components 28 and 27 showed significant signal decreases for "pain" relative to "neutral" in both groups. Component 13 was excluded from further analyses, since it failed to show significant signal change in response to "pain". For the remaining DMN components, we did not find significant between-group differences in task-relatedness. However, among BPD patients, the degree of pain-related connectivity change of component 28 was positively correlated with subjects' average BSL $(r=0.63)$ and FDS scores $(\mathrm{r}=0.59)$. This indicates that worse symptom severity and higher trait dissociation are associated with less signal decrease of the "posterior DMN" in response to painful thermal stimulation. Since both measures were correlated with each other $(r=0.52, p=$ 0.008 ), only the correlation between BSL and relative signal decrease of component 28 is shown in Figure 3.

\section{Psychophysiological Interaction Analysis}

Within-group Analyses-Using PPI analyses, we found significant within-group differences in the connectivity maps of the two seed regions: While mPFC and PCC connectivity with a set of regions implicated in the DMN was stronger during "neutral" than "pain" (eTable 4), the two seed regions showed greater connectivity with only a few brain regions during "pain" than "neutral" (eTable 5). During "neutral" greater "pain", the mPFC was significantly more correlated in both groups with adjacent voxels in the mPFC, bilateral 
$\mathrm{PCC} / \mathrm{PrC}$, and superior/middle frontal gyrus. In controls, the mPFC was also more connected to the right fusiform/parahippocampal gyrus during "neutral" than "pain". Regarding the PCC, controls showed greater connectivity during "neutral" than "pain" with adjacent voxels in the PCC/PrC, bilateral mPFC, left cerebellum, and bilateral fusiform/ parahippocampal gyrus. Among patients, enhanced connectivity of this seed region during "neutral" greater "pain" was observed with bilateral superior temporal/angular gyri and adjacent voxels in the PCC. For "pain" greater "neutral", only the patient group revealed enhanced connectivity of the PCC mPFC with the right inferior parietal lobule. In controls, we found greater correlation of the PCC during "pain" than "neutral" with left inferior frontal/superior temporal gyrus including the insula. Similarly, among patients, greater connectivity of the PCC during "pain" greater "neutral" was observed with bilateral inferior frontal/superior temporal gyri including the insula, bilateral inferior parietal lobule, left cerebellum, and left ACC.

Between-group Analyses-No brain areas showed significant between-group differences in connectivity with the mPFC for "pain" greater "neutral". For "neutral" greater "pain", controls showed significantly stronger mPFC connectivity with the left putamen (Figure 4). For the PCC, no brain areas exhibited significant between-group differences in connectivity for "neutral" greater "pain". For "pain" greater "neutral", controls showed significantly stronger PCC connectivity than the BPD group with the left DLPFC [-24, 54, $18 ; \mathrm{t}(43)=3.40 ;$ SVC-corrected $^{36}$ ] (Figure 4$) .{ }^{40}$

\section{Discussion}

To our knowledge, this is the first study to explore DMN connectivity during pain processing in patients with BPD, linking the previously separate research areas of DMN connectivity and altered pain perception in BPD. When compared to HC, patients with BPD showed significant alterations in DMN connectivity as determined by both ICA and PPI. Although the two methods are distinct in terms of methodology, ${ }^{21}$ we observed considerable overlap between the functional networks represented by components 27 and 28 and the PPI within-group results for "neutral" greater "pain". Here, both methods clearly depict the functional architecture of DMN subnetworks. ${ }^{21}$ With regard to pain-related connectivity changes, ICA and PPI revealed different, but complementary aspects of DMN dysfunction and under-connectivity in BPD patients. Given that both methods revealed alterations involving the RSC/PCC, it may even be possible that the different aspects influence each other via this central node.

\section{Independent Component Analysis}

Using ICA, we first identified three components that closely resembled our mask and included brain areas previously associated with the DMN. ${ }^{20}$ This differentiation supports the hypothesis that the DMN is more heterogeneous than widely assumed, and is in line with previous ICA studies that have identified separate DMN subnetworks with partially overlapping regions but distinctive time courses and connectivity patterns. ${ }^{26,52,61}$.

An examination of the component spatial maps revealed reduced connectivity of the left RSC, right ITG and left SFG with other DMN regions in patients compared to controls. The 
RSC and neighboring PCC have previously been implicated in assessing the (emotional) salience and self-relevance of experimental stimuli, ${ }^{62-65}$ while the ITG has been linked to visual processing, multisensory integration and dissociative pathology. ${ }^{66-68}$ Although the SFG is not commonly associated with the DMN, a recent study has shown increased coupling of this region with the dorsal and ventral mPFC during self-relevant processing. ${ }^{28}$ Due to its connections with the thalamus and the medial temporal lobe memory system, the RSC/PCC have been considered a critical hub for the integration of responses and the "switching" between different modes of processing..$^{20,69,70}$ Taken together, we speculate that abnormal RSC/PCC connectivity may be related to difficulties of BPD patients to perceive painful stimuli as self-relevant and consequently switch from a baseline state of brain function to task-related states of information processing.

Our analysis of ICA time courses further indicates that this switching might be compromised in BPD, and that the extent of the deficiency reflects clinical measures of BPD. Specifically, the higher a patient scored on measures of symptom severity and trait dissociation, the less signal decrease was observed in her "posterior DMN" in response to "pain". As recently discussed by Congdon et al., ${ }^{71}$ attenuated DMN signal decrease during task performance may underlie impaired attentional and inhibitory control, and may therefore interfere with task-specific attention and goal-directed action. ${ }^{23,71}$ Since the analysis of beta-weights pertains to the component as a whole, we cannot infer that the difference in connectivity strength with the RSC is responsible for the attenuated signal decrease. However, in light of studies implicating the RSC in consciousness and reflective self-awareness, ${ }^{72-76}$ as well as in the switching between conditions, ${ }^{69,70}$ it would be plausible for the two observations to be connected.

\section{Psychophysiological Interaction Analysis}

Within-group Analyses-In accordance with previous reports of DMN heterogeneity, our PPI analyses revealed significant within-group differences in the connectivity maps of the PCC and mPFC. ${ }^{26}$ In both groups, the two seed regions showed enhanced connectivity with other DMN regions during "neutral" greater "pain", replicating findings by Bluhm et al. ${ }^{77}$ In contrast, for "pain" greater "neutral", only the BPD group showed enhanced mPFC connectivity with the right inferior parietal lobule. Regarding the PCC, both groups displayed increased connectivity for "pain" greater "neutral" with brain areas implicated in sensory integration and pain processing. ${ }^{30,78,79}$ The latter further supports the idea that the PCC functions as a "convergence node" within the DMN - or the brain in general, where information integration and the interaction between different subsystems are facilitated. ${ }^{20,62,63}$

Between-group Analyses-Despite the abovementioned within-group differences, no brain areas showed significant between-group differences in connectivity with the mPFC for "pain" greater "neutral". For "neutral" greater "pain", controls showed significantly stronger mPFC connectivity with the left putamen. As part of the basal ganglia, the putamen has been implicated in motor control and various types of learning, e.g. reinforcement learning. ${ }^{80-82}$ Our finding of enhanced mPFC connectivity with this region during "neutral" greater "pain" in controls versus patients may reflect underlying differences in the ability to regulate/inhibit 
motor responses. Regarding the PCC, no brain areas exhibited significant between-group differences in connectivity for "neutral" greater "pain". However, during "pain" greater "neutral", controls showed significantly stronger PCC connectivity than patients with the left DLPFC. Activity in the DLPFC has been linked to response selection/inhibition, executive function, and cognitive control in the realms of emotion regulation, pain processing ${ }^{83}$ and (working) memory ${ }^{84-86}$ - all of which are affected in BPD. ${ }^{11,14,87,88}$ In a study by Koenigsberg et al., ${ }^{15}$ both BPD patients and HC showed joint recruitment of the DLPFC and PCC/PrC (among other regions) when attempting to downregulate negative emotions via psychological distancing. However, BPD patients engaged these cognitive control regions to a lesser extent than controls did, ${ }^{15}$ which is in line with our current findings.

The notion that the PCC interacts with the DLPFC to regulate emotions is also supported by Kraus et al. who reported a significant BOLD signal increase in the DLPFC and PCC in BPD patients, while they were imagining the emotional and cognitive reactions to a stressful situation. ${ }^{89}$ Hence, we speculate that the significant between-group difference in PCC connectivity with the DLPFC for "pain" greater "neutral" may reflect altered cognitive modulation of the painful stimuli. This, in turn, may be due to (1) a diminished capacity for emotion regulation, leading to such severe behavioral consequences as SIB and dissociation, and/or (2) a different appraisal of the painful stimuli as less self-relevant and aversive. The former interpretation receives support from extant data linking frontolimbic dysfunction to emotional instability in BPD. ${ }^{14,88}$ The latter, on the other hand, is in line with the role of the DMN in self-related processing and the idea that pain may be associated with reward/ negative reinforcement among BPD patients who self-injure to end states of aversive inner tension and dissociation. ${ }^{6,89}$ Taken together, we speculate that, although both groups experience the sensory component of pain and give pain ratings, their subjective experience may be qualitatively different. In other words, painful stimulation may have a different impact on the self-monitoring system of BPD patients: Whereas controls are more likely to experience pain as an aversive threat that has to be avoided or down-regulated (thus engaging the DLPFC), pain may actually be perceived as soothing by patients with BPD. ${ }^{6,7}$ However, these interpretations should be considered speculative since we did not include a detailed assessment of the subjective unpleasantness and self-relevance of the stimuli.

\section{Limitations}

There are several limitations of the present study.

First, because the majority of patients had a history of SIB, it cannot be determined whether our findings are related to SIB per se or BPD psychopathology in general. Longitudinal studies comparing BPD patients with SIB to BPD patients who never self-injured are needed to resolve this issue.

It should also be noted that controls and patients differed significantly in their average intensity ratings for the "pain" blocks during the fMRI acquisition as compared to the psychophysiological assessment prior to the fMRI scan. The individual adjustment of temperatures was conducted immediately before fMRI scanning. During scanning, individual ratings were repeated and may differ from pre-scanning ratings, as was the case 
here for HC. To control for these differences in subjective pain intensity, we entered each subject's average pain rating for the individually-adjusted temperature as a covariate into the PPI between-group comparisons for "pain" greater "neutral". Given that the actual temperature stimuli were higher for BPD patients, it may also be possible that the observed group differences represent differences in stimulus intensity rather than basic group differences in connectivity. However, this explanation is unlikely because responses in prefrontal and parietal brain regions have been related to stimulus perception and subsequent cognitive processing irrespective of perceived pain or stimulus intensity. ${ }^{33,90}$ Thus, we decided to control only for the differences in subjective pain intensity.

Moreover, since alterations in DMN connectivity and/or pain processing have also been reported in other psychiatric disorders, ${ }^{91}$ such as depression, ${ }^{92,93}$ PTSD related to early life trauma,${ }^{94}$ and social anxiety disorder,${ }^{95}$ the interpretation of our findings may be limited by the presence of such comorbidities in our patient sample. Thus, future studies should include other clinical control groups to clarify whether our findings are specific to BPD.

Although ICA and PPI analyses are well-established and provide useful complements to traditional GLM subtraction analyses, it is important to acknowledge different sources of investigator-specific bias and thus variability in their outcomes. ${ }^{21,96}$ Potential biases result from the a priori selection of seed regions in PPI and the use of different model orders and spatial templates in ICA. Similarly, although DMN connectivity during pain, rather than pain processing per se, was the main focus of the current study, our PPI results are limited by modeling the connections of only two seed regions. It is possible, for example, that the interaction between the PCC and DLPFC could be mediated through a third area, or that a third area may provide common input to both. ${ }^{58}$ According to Friston et al., ${ }^{58}$ this common input would itself be context-sensitive and could be identified using PPI analysis with the third area as the seed region. Hence, given the pivotal role of the anterior and midcingulate cortices in pain processing and their connections with both the PCC and prefrontal cortex ${ }^{34,64}$ future studies should place additional seeds in those cingulate regions.

Finally, further research is necessary to determine whether the observed alterations in DMN connectivity in BPD are limited to painful thermal stimulation or if they generalize to other tasks, such as the processing of social and autobiographical stimuli, for example. ${ }^{97}$ Since BPD patients tend to over-interpret neutral or ambiguous stimuli as self-referential, ${ }^{92,103}$ one could test the hypothesis that group differences in DMN connectivity are, in fact, mediated by a different appraisal of the stimuli as (more or less) self-relevant and aversive.

\section{Conclusion}

In summary, the present evidence suggests that patients with BPD show significant alterations in DMN connectivity with differences in spatial integrity and temporal characteristics. These alterations may reflect a different cognitive and affective appraisal of pain as less self-relevant and aversive, and a deficiency in the switching between baseline and task-related processing. This deficiency may, in turn, be related to everyday difficulties of BPD patients to regulate their emotions, focus mindfully on one task at a time, and efficiently shift their attention from one task to another. ${ }^{98,99}$ Hence, the present results may be incorporated into the advancement of mindfulness-based treatments, such as dialectical 
behavior therapy, ${ }^{100,101}$ to help BPD patients engage in an activity with full alertness and awareness of themselves and their bodily sensations.

\section{Supplementary Material}

Refer to Web version on PubMed Central for supplementary material.

\section{References}

1. Stiglmayr CE, Shapiro DA, Stieglitz RD, Limberger MF, Bohus M. Experience of aversive tension and dissociation in female patients with borderline personality disorder -- a controlled study. $\mathrm{J}$ Psychiatr Res. Mar-Apr;2001 35(2):111-118. [PubMed: 11377440]

2. Stiglmayr CE, Grathwol T, Linehan MM, Ihorst G, Fahrenberg J, Bohus M. Aversive tension in patients with borderline personality disorder: a computer-based controlled field study. Acta Psychiatr Scand. May; 2005 111(5):372-379. [PubMed: 15819731]

3. Lieb K, Zanarini MC, Schmahl C, Linehan MM, Bohus M. Borderline personality disorder. Lancet. Jul 31; Aug 31; 2004 364(9432):453-461. [PubMed: 15288745]

4. Ludascher P, Bohus M, Lieb K, Philipsen A, Jochims A, Schmahl C. Elevated pain thresholds correlate with dissociation and aversive arousal in patients with borderline personality disorder. Psychiatry Res. Jan 15; 2007 149(1-3):291-296. [PubMed: 17126914]

5. Shearer SL. Phenomenology of self-injury among inpatient women with borderline personality disorder. J Nerv Ment Dis. Sep; 1994 182(9):524-526. [PubMed: 8083682]

6. Kleindienst N, Bohus M, Ludascher P, Limberger MF, Kuenkele K, Ebner-Priemer UW, Chapman AL, Reicherzer M, Stieglitz RD, Schmahl C. Motives for nonsuicidal self-injury among women with borderline personality disorder. J Nerv Ment Dis. Mar; 2008 196(3):230-236. [PubMed: 18340259]

7. Niedtfeld I, Schulze L, Kirsch P, Herpertz SC, Bohus M, Schmahl C. Affect regulation and pain in borderline personality disorder: a possible link to the understanding of self-injury. Biol Psychiatry. Aug 15; 2010 68(4):383-391. [PubMed: 20537612]

8. Bohus M, Limberger M, Ebner U, Glocker FX, Schwarz B, Wernz M, Lieb K. Pain perception during self-reported distress and calmness in patients with borderline personality disorder and selfmutilating behavior. Psychiatry Res. Sep 11; 2000 95(3):251-260. [PubMed: 10974364]

9. Russ MJ, Roth SD, Lerman A, Kakuma T, Harrison K, Shindledecker RD, Hull J, Mattis S. Pain perception in self-injurious patients with borderline personality disorder. Biol Psychiatry. Sep 15; 1992 32(6):501-511. [PubMed: 1445967]

10. Schmahl C, Greffrath W, Baumgartner U, Schlereth T, Magerl W, Philipsen A, Lieb K, Bohus M, Treede RD. Differential nociceptive deficits in patients with borderline personality disorder and self-injurious behavior: laser-evoked potentials, spatial discrimination of noxious stimuli, and pain ratings. Pain. Jul; 2004 110(1-2):470-479. [PubMed: 15275800]

11. Schmahl C, Bohus M, Esposito F, Treede RD, Di Salle F, Greffrath W, Ludaescher P, Jochims A, Lieb K, Scheffler K, Hennig J, Seifritz E. Neural correlates of antinociception in borderline personality disorder. Arch Gen Psychiatry. Jun; 2006 63(6):659-667. [PubMed: 16754839]

12. Kraus A, Esposito F, Seifritz E, Di Salle F, Ruf M, Valerius G, Ludaescher P, Bohus M, Schmahl C. Amygdala deactivation as a neural correlate of pain processing in patients with borderline personality disorder and co-occurrent posttraumatic stress disorder. Biol Psychiatry. May 1; 2009 65(9):819-822. [PubMed: 19058793]

13. New AS, Hazlett EA, Buchsbaum MS, Goodman M, Mitelman SA, Newmark R, Trisdorfer R, Haznedar MM, Koenigsberg HW, Flory J, Siever LJ. Amygdala-prefrontal disconnection in borderline personality disorder. Neuropsychopharmacology. Jul; 2007 32(7):1629-1640. [PubMed: 17203018]

14. Silbersweig D, Clarkin JF, Goldstein M, Kernberg OF, Tuescher O, Levy KN, Brendel G, Pan H, Beutel M, Pavony MT, Epstein J, Lenzenweger MF, Thomas KM, Posner MI, Stern E. Failure of frontolimbic inhibitory function in the context of negative emotion in borderline personality disorder. Am J Psychiatry. Dec; 2007 164(12):1832-1841. [PubMed: 18056238] 
15. Koenigsberg HW, Fan J, Ochsner KN, Liu X, Guise KG, Pizzarello S, Dorantes C, Guerreri S, Tecuta L, Goodman M, New A, Siever LJ. Neural correlates of the use of psychological distancing to regulate responses to negative social cues: a study of patients with borderline personality disorder. Biol Psychiatry. Nov 1; 2009 66(9):854-863. [PubMed: 19651401]

16. Gusnard DA, Akbudak E, Shulman GL, Raichle ME. Medial prefrontal cortex and self-referential mental activity: relation to a default mode of brain function. Proc Natl Acad Sci U S A. Mar 27; 2001 98(7):4259-4264. [PubMed: 11259662]

17. Northoff G, Heinzel A, de Greck M, Bermpohl F, Dobrowolny H, Panksepp J. Self-referential processing in our brain--a meta-analysis of imaging studies on the self. Neuroimage. May 15; 2006 31(1):440-457. [PubMed: 16466680]

18. Schneider F, Bermpohl F, Heinzel A, Rotte M, Walter M, Tempelmann C, Wiebking C, Dobrowolny H, Heinze HJ, Northoff G. The resting brain and our self: self-relatedness modulates resting state neural activity in cortical midline structures. Neuroscience. Nov 11; 2008 157(1):120131. [PubMed: 18793699]

19. Mantini D, Caulo M, Ferretti A, Romani GL, Tartaro A. Noxious somatosensory stimulation affects the default mode of brain function: evidence from functional MR imaging. Radiology. Dec; 2009 253(3):797-804. [PubMed: 19789220]

20. Buckner RL, Andrews-Hanna JR, Schacter DL. The brain's default network: anatomy, function, and relevance to disease. Ann. N. Y. Acad. Sci. Mar.2008 1124:1-38. [PubMed: 18400922]

21. Zhang D, Raichle ME. Disease and the brain's dark energy. Nat Rev Neurol. Jan; 2010 6(1):15-28. [PubMed: 20057496]

22. Bluhm RL, Osuch EA, Lanius RA, Boksman K, Neufeld RW, Theberge J, Williamson P. Default mode network connectivity: effects of age, sex, and analytic approach. Neuroreport. May 28; 2008 19(8):887-891. [PubMed: 18463507]

23. Mason MF, Norton MI, Van Horn JD, Wegner DM, Grafton ST, Macrae CN. Wandering minds: the default network and stimulus-independent thought. Science. Jan 19; 2007 315(5810):393-395. [PubMed: 17234951]

24. Raichle ME, Gusnard DA. Intrinsic brain activity sets the stage for expression of motivated behavior. J Comp Neurol. Dec 5; 2005 493(1):167-176. [PubMed: 16254998]

25. Raichle ME. Two views of brain function. Trends Cogn Sci. Apr; 2010 14(4):180-190. [PubMed: 20206576]

26. Uddin LQ, Kelly AM, Biswal BB, Xavier Castellanos F, Milham MP. Functional connectivity of default mode network components: correlation, anticorrelation, and causality. Hum Brain Mapp. Feb; 2009 30(2):625-637. [PubMed: 18219617]

27. Fox MD, Snyder AZ, Vincent JL, Corbetta M, Van Essen DC, Raichle ME. The human brain is intrinsically organized into dynamic, anticorrelated functional networks. Proc Natl Acad Sci U S A. Jul 5; 2005 102(27):9673-9678. [PubMed: 15976020]

28. van Buuren M, Gladwin TE, Zandbelt BB, Kahn RS, Vink M. Reduced functional coupling in the default-mode network during self-referential processing. Hum Brain Mapp. Aug; 2010 31(8): 1117-1127. [PubMed: 20108218]

29. Andrews-Hanna JR, Reidler JS, Sepulcre J, Poulin R, Buckner RL. Functional-anatomic fractionation of the brain's default network. Neuron. Feb 25; 2010 65(4):550-562. [PubMed: 20188659]

30. Apkarian AV, Bushnell MC, Treede RD, Zubieta JK. Human brain mechanisms of pain perception and regulation in health and disease. Eur J Pain. Aug; 2005 9(4):463-484. [PubMed: 15979027]

31. Treede RD, Kenshalo DR, Gracely RH, Jones AK. The cortical representation of pain. Pain. Feb; 1999 79(2-3):105-111. [PubMed: 10068155]

32. Kong J, Loggia ML, Zyloney C, Tu P, Laviolette P, Gollub RL. Exploring the brain in pain: activations, deactivations and their relation. Pain. Feb; 2010 148(2):257-267. [PubMed: 20005043]

33. Coghill RC, Sang CN, Maisog JM, Iadarola MJ. Pain intensity processing within the human brain: a bilateral, distributed mechanism. J Neurophysiol. Oct; 1999 82(4):1934-1943. [PubMed: 10515983] 
34. Vogt BA, Derbyshire S, Jones AK. Pain processing in four regions of human cingulate cortex localized with co-registered PET and MR imaging. Eur J Neurosci. Jul; 1996 8(7):1461-1473. [PubMed: 8758953]

35. Rainville P, Duncan GH, Price DD, Carrier B, Bushnell MC. Pain affect encoded in human anterior cingulate but not somatosensory cortex. Science. Aug 15; 1997 277(5328):968-971. [PubMed: 9252330]

36. Wolf RC, Sambataro F, Vasic N, Schmid M, Thomann PA, Bienentreu SD, Wolf ND. Aberrant connectivity of resting-state networks in borderline personality disorder. J Psychiatry Neurosci. Mar 1.2011 36(2):100150.

37. First, MB.; Spitzer, RL.; Gibbon, M.; Williams, JBW. Structured Clinical Interview for Axis I DSM-IV Disorders - Patient Edition (SCID-I/P). American Psychiatric Press; New York: 1995.

38. Loranger, AW. International Personality Disorder Examination (IPDE): DSM-IV and ICD-10 Modules. Psychological Assessment Resources; Odessa, Florida: 1999.

39. Freyberger, HJ.; Spitzer, C.; Stieglitz, RD. Fragebogen zu Dissoziativen Symptomen (FDS): Deutsche Adaptation, Reliabilität und Validität der amerikanischen Dissociative Experience Scale (DES) [German adaptation, reliability and validity of the Dissociative Experience Scale (DES)]. Huber; Bern, Switzerland: 1999.

40. Stiglmayr CE, Braakmann D, Haaf B, Stieglitz RD, Bohus M. Development and characteristics of Dissociation-Tension-Scale acute (DSS-Akute). Psychother Psychosom Med Psychol. Jul; 2003 53(7):287-294. [PubMed: 12847662]

41. Bohus M, Limberger MF, Frank U, Sender I, Gratwohl T, Stieglitz RD. Development of the Borderline Symptom List. Psychother Psychosom Med Psychol. May; 2001 51(5):201-211. [PubMed: 11417358]

42. Bohus M, Limberger MF, Frank U, Chapman AL, Kuhler T, Stieglitz RD. Psychometric properties of the Borderline Symptom List (BSL). Psychopathology. 2007; 40(2):126-132. [PubMed: 17215599]

43. Bell AJ, Sejnowski TJ. An information-maximization approach to blind separation and blind deconvolution. Neural Comput. Nov; 1995 7(6):1129-1159. [PubMed: 7584893]

44. Calhoun VD, Adali T, Pearlson GD, Pekar JJ. A method for making group inferences from functional MRI data using independent component analysis. Hum Brain Mapp. Nov; 2001 14(3): 140-151. [PubMed: 11559959]

45. Calhoun VD, Liu J, Adali T. A review of group ICA for fMRI data and ICA for joint inference of imaging, genetic, and ERP data. Neuroimage. Mar; 2009 45(1 Suppl):S163-172. [PubMed: 19059344]

46. Li YO, Adali T, Calhoun VD. Estimating the number of independent components for functional magnetic resonance imaging data. Hum Brain Mapp. Nov; 2007 28(11):1251-1266. [PubMed: 17274023]

47. Himberg J, Hyvarinen A, Esposito F. Validating the independent components of neuroimaging time series via clustering and visualization. Neuroimage. Jul; 2004 22(3):1214-1222. [PubMed: 15219593]

48. Beckmann CF, DeLuca M, Devlin JT, Smith SM. Investigations into resting-state connectivity using independent component analysis. Philos Trans R Soc Lond B Biol Sci. May 29; 2005 360(1457):1001-1013. [PubMed: 16087444]

49. Calhoun VD, Kiehl KA, Pearlson GD. Modulation of temporally coherent brain networks estimated using ICA at rest and during cognitive tasks. Hum Brain Mapp. Jul; 2008 29(7):828838. [PubMed: 18438867]

50. Stevens MC, Kiehl KA, Pearlson G, Calhoun VD. Functional neural circuits for mental timekeeping. Hum Brain Mapp. May; 2007 28(5):394-408. [PubMed: 16944489]

51. Jafri MJ, Pearlson GD, Stevens M, Calhoun VD. A method for functional network connectivity among spatially independent resting-state components in schizophrenia. Neuroimage. Feb 15; 2008 39(4):1666-1681. [PubMed: 18082428]

52. Assaf M, Jagannathan K, Calhoun VD, Miller L, Stevens MC, Sahl R, O’Boyle JG, Schultz RT, Pearlson GD. Abnormal functional connectivity of default mode subnetworks in autism spectrum disorder patients. Neuroimage. Oct 15; 2010 53(1):247-256. [PubMed: 20621638] 
53. Garrity AG, Pearlson GD, McKiernan K, Lloyd D, Kiehl KA, Calhoun VD. Aberrant "default mode" functional connectivity in schizophrenia. A?. J. Psychiatry. Mar; 2007 164(3):450-457.

54. Hayasaka S, Nichols TE. Combining voxel intensity and cluster extent with permutation test framework. Neuroimage. Sep; 2004 23(1):54-63. [PubMed: 15325352]

55. Otti A, Guendel H, Laer L, Wohlschlaeger AM, Lane RD, Decety J, Zimmer C, Henningsen P, Noll-Hussong M. I know the pain you feel-how the human brain's default mode predicts our resonance to another's suffering. Neuroscience. Aug 11; 2010 169(1):143-148. [PubMed: 20450959]

56. Kim DI, Mathalon DH, Ford JM, Mannell M, Turner JA, Brown GG, Belger A, Gollub R, Lauriello J, Wible C, O’Leary D, Lim K, Toga A, Potkin SG, Birn F, Calhoun VD. Auditory oddball deficits in schizophrenia: an independent component analysis of the fMRI multisite function BIRN study. Schizophr Bull. Jan; 2009 35(1):67-81. [PubMed: 19074498]

57. Kim DI, Manoach DS, Mathalon DH, Turner JA, Mannell M, Brown GG, Ford JM, Gollub RL, White T, Wible C, Belger A, Bockholt HJ, Clark VP, Lauriello J, O'Leary D, Mueller BA, Lim KO, Andreasen N, Potkin SG, Calhoun VD. Dysregulation of working memory and default-mode networks in schizophrenia using independent component analysis, an fBIRN and MCIC study. Hum Brain Mapp. Nov; 2009 30(11):3795-3811. [PubMed: 19434601]

58. Friston KJ, Buechel C, Fink GR, Morris J, Rolls E, Dolan RJ. Psychophysiological and modulatory interactions in neuroimaging. Neuroimage. Oct; 1997 6(3):218-229. [PubMed: 9344826]

59. Fransson P. Spontaneous low-frequency BOLD signal fluctuations: an fMRI investigation of the resting-state default mode of brain function hypothesis. Hum. Brain Mapp. Sep; 2005 26(1):15-29. [PubMed: 15852468]

60. Ethofer T, Gschwind M, Vuilleumier P. Processing social aspects of human gaze: a combined fMRI-DTI study. Neuroimage. Mar 1; 2011 55(1):411-419. [PubMed: 21095230]

61. Allen EA, Erhardt EB, Damaraju E, Gruner W, Segall JM, Silva RF, Havlicek M, Rachakonda S, Fries J, Kalyanam R, Michael AM, Caprihan A, Turner JA, Eichele T, Adelsheim S, Bryan AD, Bustillo J, Clark VP, Feldstein Ewing SW, Filbey F, Ford CC, Hutchison K, Jung RE, Kiehl KA, Kodituwakku P, Komesu YM, Mayer AR, Pearlson GD, Phillips JP, Sadek JR, Stevens M, Teuscher U, Thoma RJ, Calhoun VD. A baseline for the multivariate comparison of resting-state networks. Front Syst Neurosci. 2011; 5:2. [PubMed: 21442040]

62. Maddock RJ. The retrosplenial cortex and emotion: new insights from functional neuroimaging of the human brain. Trends Neurosci. Jul; 1999 22(7):310-316. [PubMed: 10370255]

63. Nielsen FA, Balslev D, Hansen LK. Mining the posterior cingulate: segregation between memory and pain components. Neuroimage. Sep; 2005 27(3):520-532. [PubMed: 15946864]

64. Vogt BA. Pain and emotion interactions in subregions of the cingulate gyrus. Nat Rev Neurosci. Jul; 2005 6(7):533-544. [PubMed: 15995724]

65. Vann SD, Aggleton JP, Maguire EA. What does the retrosplenial cortex do? Nat Rev Neurosci. Nov; 2009 10(11):792-802. [PubMed: 19812579]

66. Herath P, Kinomura S, Roland PE. Visual recognition: evidence for two distinctive mechanisms from a PET study. Hum Brain Mapp. Feb; 2001 12(2):110-119. [PubMed: 11169875]

67. Ludascher P, Valerius G, Stiglmayr C, Mauchnik J, Lanius RA, Bohus M, Schmahl C. Pain sensitivity and neural processing during dissociative states in patients with borderline personality disorder with and without comorbid posttraumatic stress disorder: a pilot study. J Psychiatry Neurosci. May; 2010 35(3):177-184. [PubMed: 20420768]

68. Mesulam MM. From sensation to cognition. Brain. Jun; 1998 121(Pt 6):1013-1052. [PubMed: 9648540]

69. Fransson P, Marrelec G. The precuneus/posterior cingulate cortex plays a pivotal role in the default mode network: Evidence from a partial correlation network analysis. Neuroimage. Sep 1; 2008 42(3):1178-1184. [PubMed: 18598773]

70. Daniels JK, McFarlane AC, Bluhm RL, Moores KA, Clark CR, Shaw ME, Williamson PC, Densmore M, Lanius RA. Switching between executive and default mode networks in posttraumatic stress disorder: alterations in functional connectivity. J. Psychiatry Neurosci. Jul; 2010 35(4):258-266. [PubMed: 20569651] 
71. Congdon E, Mumford JA, Cohen JR, Galvan A, Aron AR, Xue G, Miller E, Poldrack RA. Engagement of large-scale networks is related to individual differences in inhibitory control. Neuroimage. Nov 1; 2010 53(2):653-663. [PubMed: 20600962]

72. Fiset P, Paus T, Daloze T, Plourde G, Meuret P, Bonhomme V, Hajj-Ali N, Backman SB, Evans AC. Brain mechanisms of propofol-induced loss of consciousness in humans: a positron emission tomographic study. J Neurosci. Jul 1; 1999 19(13):5506-5513. [PubMed: 10377359]

73. Laureys S, Goldman S, Phillips C, Van Bogaert P, Aerts J, Luxen A, Franck G, Maquet P. Impaired effective cortical connectivity in vegetative state: preliminary investigation using PET. Neuroimage. Apr; 1999 9(4):377-382. [PubMed: 10191166]

74. Kjaer TW, Nowak M, Lou HC. Reflective self-awareness and conscious states: PET evidence for a common midline parietofrontal core. Neuroimage. Oct; 2002 17(2):1080-1086. [PubMed: 12377180]

75. Demertzi A, Soddu A, Faymonville ME, Bahri MA, Gosseries O, Vanhaudenhuyse A, Phillips C, Maquet P, Noirhomme Q, Luxen A, Laureys S. Hypnotic modulation of resting state fMRI default mode and extrinsic network connectivity. Prog Brain Res. 2011; 193:309-322. [PubMed: 21854971]

76. Vogt BA, Laureys S. Posterior cingulate, precuneal and retrosplenial cortices: cytology and components of the neural network correlates of consciousness. Prog Brain Res. 2005; 150:205217. [PubMed: 16186025]

77. Bluhm RL, Clark CR, McFarlane AC, Moores KA, Shaw ME, Lanius RA. Default network connectivity during a working memory task. Hum. Brain Mapp. Jul 20.2010

78. Clower DM, West RA, Lynch JC, Strick PL. The inferior parietal lobule is the target of output from the superior colliculus, hippocampus, and cerebellum. J Neurosci. Aug 15; 2001 21(16): 6283-6291. [PubMed: 11487651]

79. Craig AD. How do you feel--now? The anterior insula and human awareness. Nat Rev Neurosci. Jan; 2009 10(1):59-70. [PubMed: 19096369]

80. Alexander GE, Crutcher MD. Preparation for movement: neural representations of intended direction in three motor areas of the monkey. J Neurophysiol. Jul; 1990 64(1):133-150. [PubMed: 2388061]

81. DeLong MR, Alexander GE, Georgopoulos AP, Crutcher MD, Mitchell SJ, Richardson RT. Role of basal ganglia in limb movements. Hum Neurobiol. 1984; 2(4):235-244. [PubMed: 6715208]

82. Packard MG, Knowlton BJ. Learning and memory functions of the basal ganglia. Annual Review of Neuroscience. 2002; 25(1):563-593.

83. Lorenz J, Minoshima S, Casey KL. Keeping pain out of mind: the role of the dorsolateral prefrontal cortex in pain modulation. Brain. May; 2003 126(Pt 5):1079-1091. [PubMed: 12690048]

84. Veen, Vv; Carter, CS. Conflict and Cognitive Control in the Brain. Current Directions in Psychological Science. Oct 1; 2006 15(5):237-240. 2006.

85. Ochsner KN, Bunge SA, Gross JJ, Gabrieli JD. Rethinking feelings: an FMRI study of the cognitive regulation of emotion. J Cogn Neurosci. Nov 15; 2002 14(8):1215-1229. [PubMed: 12495527]

86. D'Esposito M, Detre JA, Alsop DC, Shin RK, Atlas S, Grossman M. The neural basis of the central executive system of working memory. Nature. Nov 16; 1995 378(6554):279-281. [PubMed: 7477346]

87. Beblo T, Saavedra AS, Mensebach C, Lange W, Markowitsch HJ, Rau H, Woermann FG, Driessen M. Deficits in visual functions and neuropsychological inconsistency in Borderline Personality Disorder. Psychiatry Res. Dec 7; 2006 145(2-3):127-135. [PubMed: 17070927]

88. Koenigsberg HW, Siever LJ, Lee H, Pizzarello S, New AS, Goodman M, Cheng H, Flory J, Prohovnik I. Neural correlates of emotion processing in borderline personality disorder. Psychiatry Res. Jun 30; 2009 172(3):192-199. [PubMed: 19394205]

89. Kraus A, Valerius G, Seifritz E, Ruf M, Bremner JD, Bohus M, Schmahl C. Script-driven imagery of self-injurious behavior in patients with borderline personality disorder: a pilot FMRI study. Acta Psychiatr Scand. Jan; 2010 121(1):41-51. [PubMed: 19522883] 
90. Bornhovd K, Quante M, Glauche V, Bromm B, Weiller C, Buchel C. Painful stimuli evoke different stimulus-response functions in the amygdala, prefrontal, insula and somatosensory cortex: a single-trial fMRI study. Brain. Jun; 2002 125(Pt 6):1326-1336. [PubMed: 12023321]

91. Lautenbacher S, Krieg J-C. Pain perception in psychiatric disorders: A review of the literature. Journal of Psychiatric Research. 1994; 28(2):109-122. [PubMed: 7932274]

92. Grimm S, Boesiger P, Beck J, Schuepbach D, Bermpohl F, Walter M, Ernst J, Hell D, Boeker H, Northoff G. Altered negative BOLD responses in the default-mode network during emotion processing in depressed subjects. Neuropsychopharmacology. Mar; 2009 34(4):932-843. [PubMed: 18536699]

93. Bluhm R, Williamson P, Lanius R, Theberge J, Densmore M, Bartha R, Neufeld R, Osuch E. Resting state default-mode network connectivity in early depression using a seed region-of-interest analysis: decreased connectivity with caudate nucleus. Psychiatry Clin Neurosci. Dec; 2009 63(6): 754-761. [PubMed: 20021629]

94. Bluhm RL, Williamson PC, Osuch EA, Frewen PA, Stevens TK, Boksman K, Neufeld RW, Theberge J, Lanius RA. Alterations in default network connectivity in posttraumatic stress disorder related to early-life trauma. J. Psychiatry Neurosci. May; 2009 34(3):187-194. [PubMed: 19448848]

95. Liao W, Chen H, Feng Y, Mantini D, Gentili C, Pan Z, Ding J, Duan X, Qiu C, Lui S, Gong Q, Zhang W. Selective aberrant functional connectivity of resting state networks in social anxiety disorder. Neuroimage. Oct 1; 2010 52(4):1549-1558. [PubMed: 20470894]

96. Cole DM, Smith SM, Beckmann CF. Advances and pitfalls in the analysis and interpretation of resting-state FMRI data. Front Syst Neurosci. Apr.2010 4:1-15. 2010. [PubMed: 20204156]

97. Spreng RN, Mar RA, Kim AS. The common neural basis of autobiographical memory, prospection, navigation, theory of mind, and the default mode: a quantitative meta-analysis. $\mathrm{J}$ Cogn Neurosci. Mar; 2009 21(3):489-510. [PubMed: 18510452]

98. Levy KN, Beeney JE, Wasserman RH, Clarkin JF. Conflict begets conflict: Executive control, mental state vacillations, and the therapeutic alliance in treatment of borderline personality disorder. Psychother Res. Jun $15.2010: 1-10$. [PubMed: 20131148]

99. Sachse S, Keville S, Feigenbaum J. A feasibility study of mindfulness-based cognitive therapy for individuals with borderline personality disorder. Psychol Psychother. Aug 10.2010

100. Linehan MM, Armstrong HE, Suarez A, Allmon D, Heard HL. Cognitive-behavioral treatment of chronically parasuicidal borderline patients. Arch Gen Psychiatry. Dec; 1991 48(12):1060-1064. [PubMed: 1845222]

101. Linehan, MM. Cognitive-behavioural treatment of borderline personality disorder. The Guilford Press; New York: 1993. 

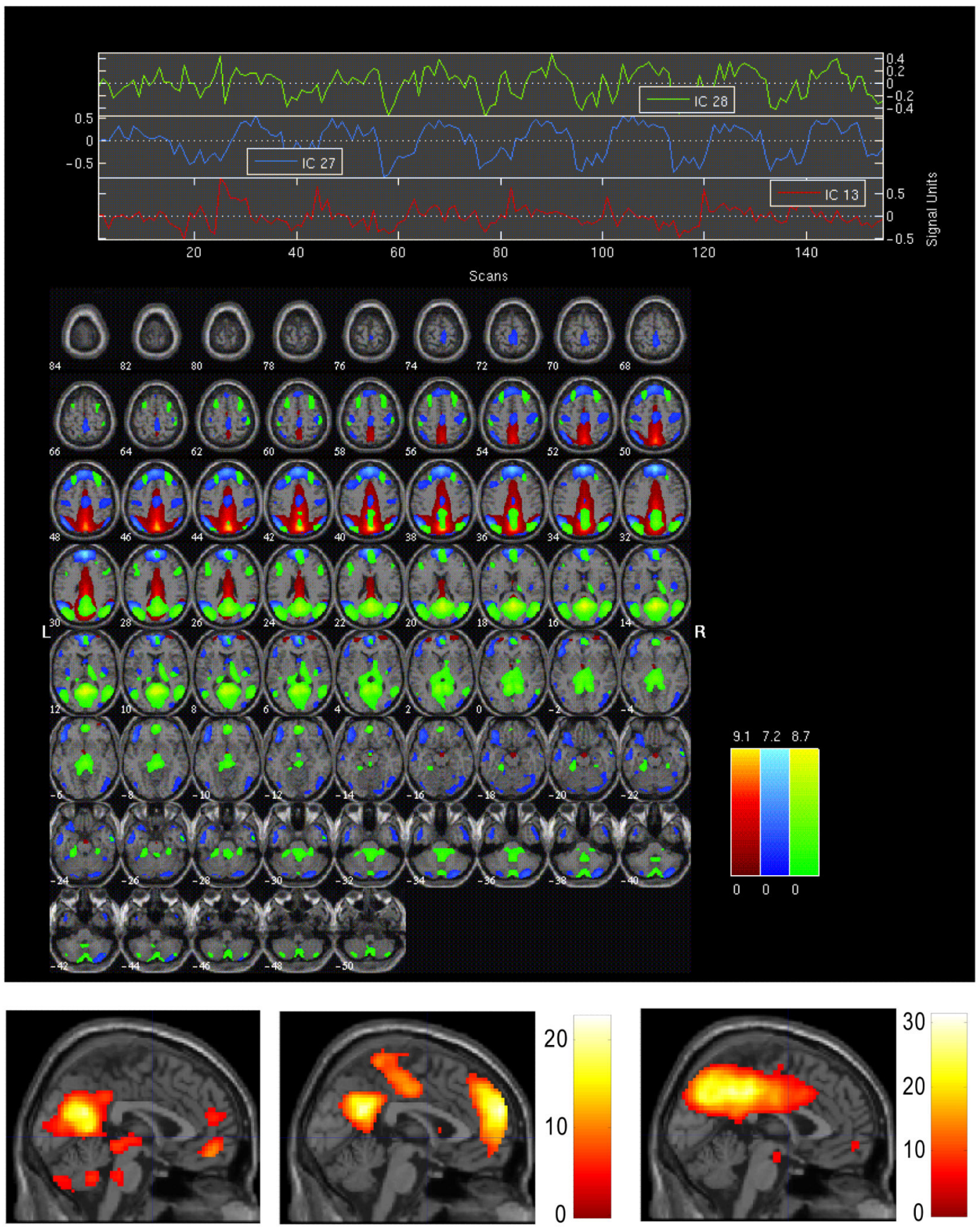

Figure 1.

The upper section depicts a composite view of the 3 ICA components representing the default mode subnetworks. These spatial maps and time courses were identified by GIFT and correspond to the mean component estimates of all 47 subjects (BPD patients and HC). The lower section shows the statistical parametric maps of these components created in SPM8. From left to right: component 28, component 27, and component 13. 

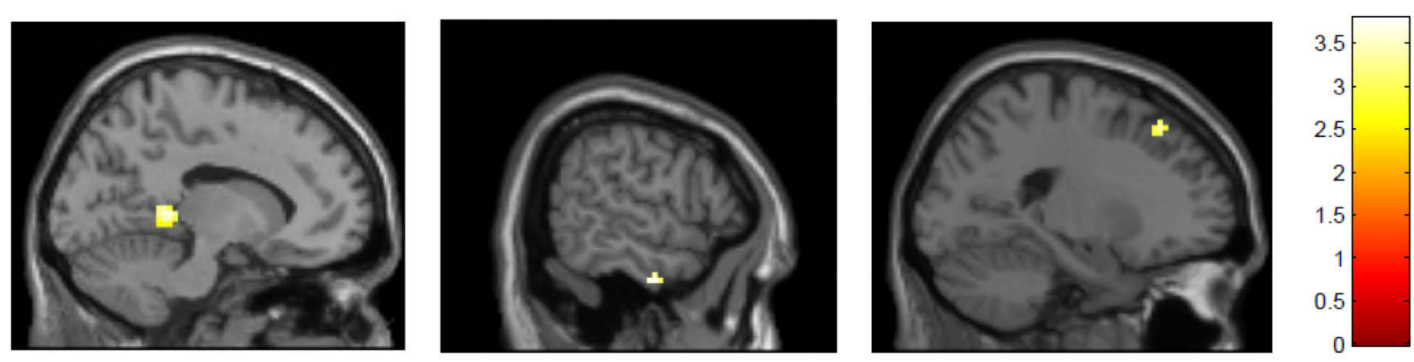

Figure 2.

Group differences in the default mode sub-networks. Compared to healthy controls, BPD patients showed significantly less integration of the left RSC $[-12,-39,3 ; \mathrm{t}(44)=4.16]$ (left) into component 28 and of the right ITG [60, -9, -33; $\mathrm{t}(44)=3.79]$ (middle) and left $\mathrm{SFG}[-21,30,51 ; \mathrm{t}(44)=3.40]$ (right) into component 27 . Each map is masked with the corresponding mask generated from all subjects (see Fig. 1) and thresholded at $\mathrm{p}<0.005$, (uncorrected) in an addition to a cluster-extent threshold based on random field theory. ${ }^{54}$ 


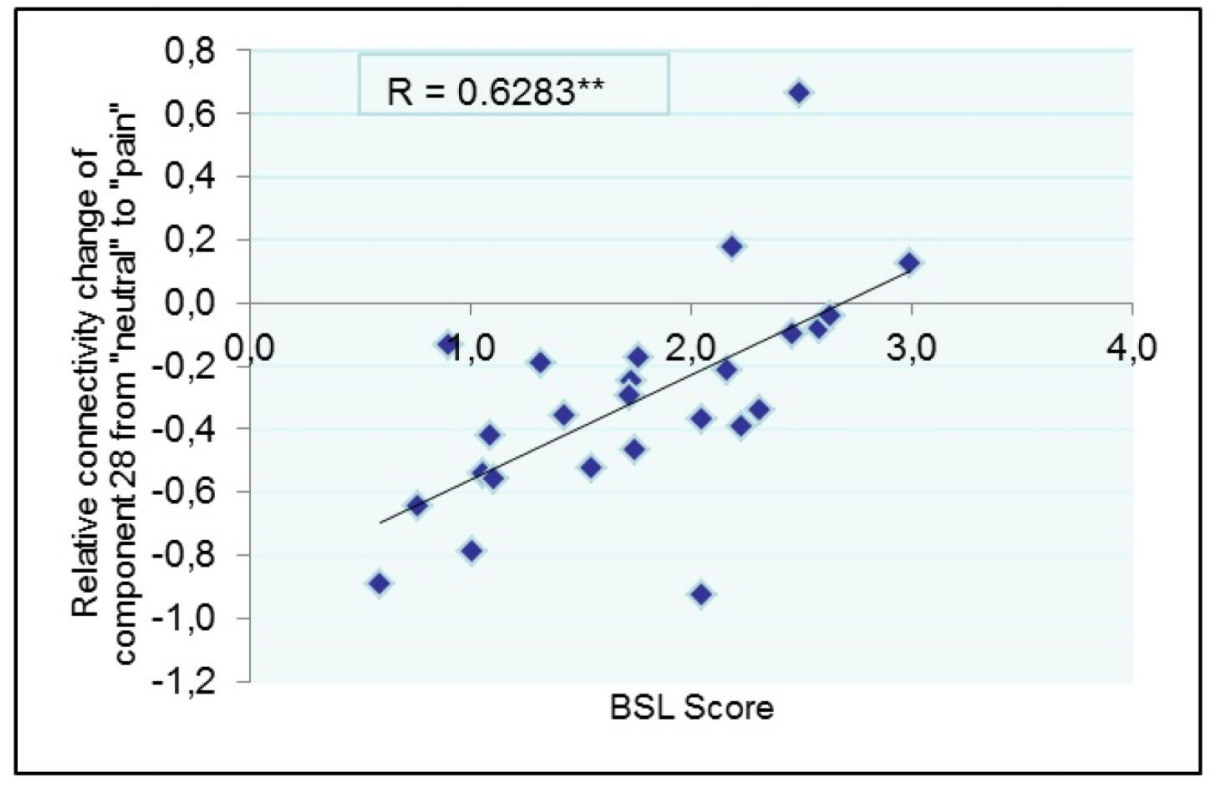

Figure 3.

The graph shows the negative correlation between the relative connectivity change of component 28 from "neutral" to "pain" and BSL scores in patients with BPD ( $p<0.05$, Bonferroni-corrected). 

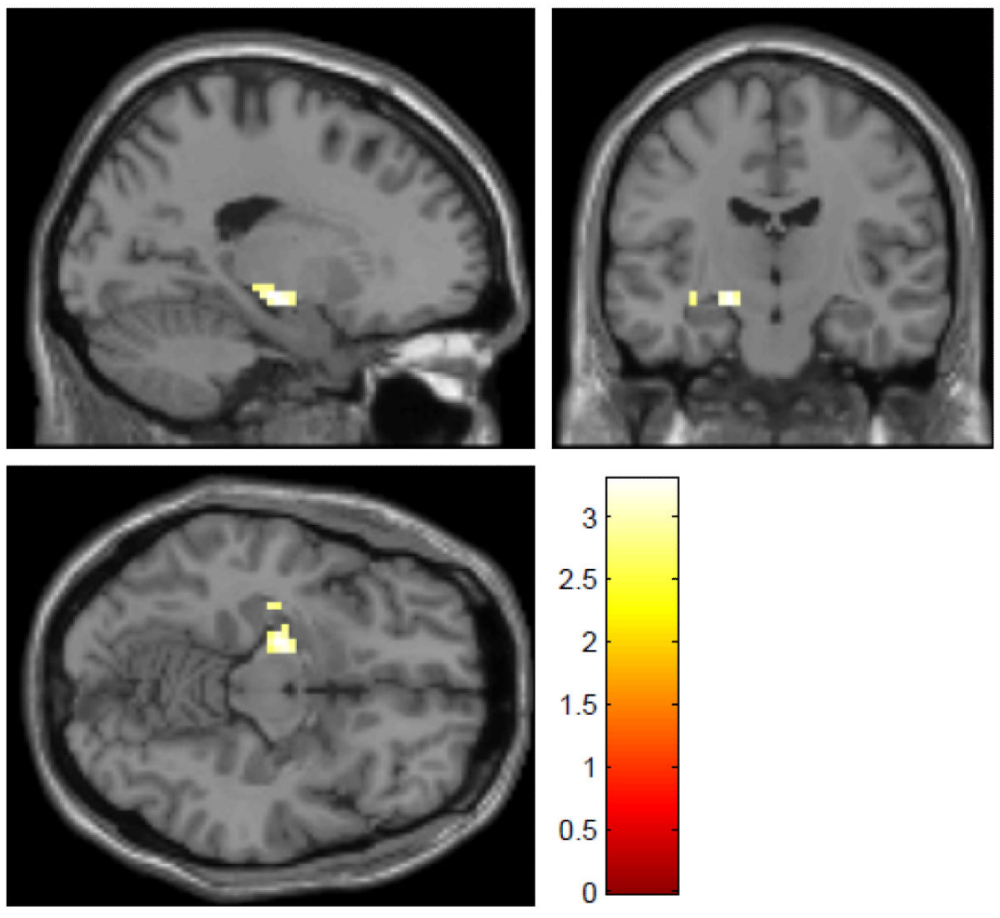

Figure 4.

Group difference in mPFC seed region connectivity. During "neutral" greater "pain", patients with BPD showed significantly less connectivity of the mPFC seed region with the left putamen $[-18,-15,-12 ; \mathrm{t}(44)=3.30]$. This cluster is significant at $\mathrm{p}<0.005$, (uncorrected) at the voxel level in an addition to a cluster-extent threshold based on random field theory. ${ }^{54}$ 

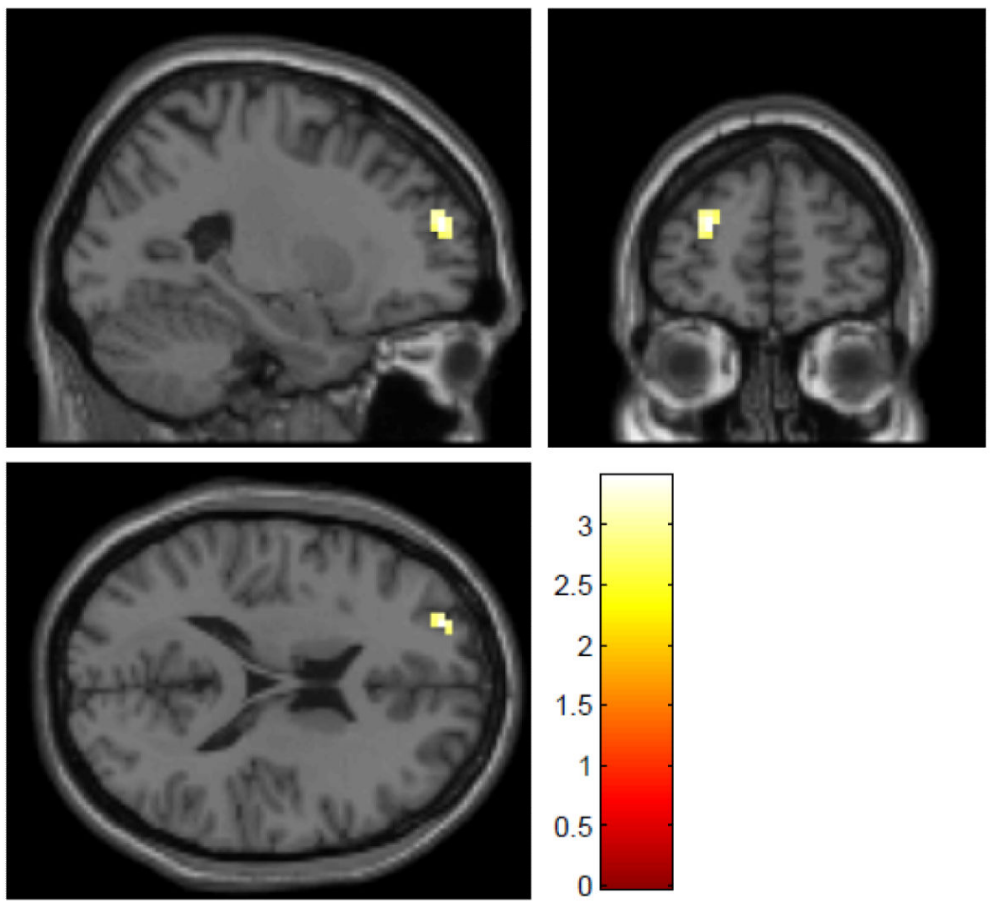

Figure 5.

Group difference in PCC seed region connectivity. During "pain" greater "neutral", patients with BPD showed significantly less connectivity of the PCC seed region with the left DLPFC $[-24,54,18 ; \mathrm{t}(43)=3.40 ; \mathrm{p}<.05$, SVC-corrected $]$. 


\section{Table 1}

\section{Demographic and Psychometric Data}

\begin{tabular}{|c|c|c|}
\hline & $\begin{array}{l}\text { Patients with BPD } \\
(\mathbf{n}=25)\end{array}$ & $\begin{array}{l}\text { Controls } \\
(\mathbf{n}=22)\end{array}$ \\
\hline Age, mean $\pm \mathrm{SD}, \mathrm{y}$ & $28.48 \pm 7.12$ & $28.23 \pm 8.37^{*}$ \\
\hline BSL score, mean \pm SD & $1.76 \pm 0.66$ & \\
\hline No. of DSM-IV BPD criteria fulfilled & $6.54 \pm 1.22$ & \\
\hline FDS score, mean \pm SD & $20.81 \pm 10.17$ & $3.38 \pm 2.58^{\dagger}$ \\
\hline DSS score, mean \pm SD & $0.65 \pm 0.82$ & $0.13 \pm 0.32^{*}$ \\
\hline Aversive inner tension & $3.44 \pm 2.14$ & $1.00 \pm 1.38^{\dagger}$ \\
\hline Current SIB ([past] No.) & $17[6]$ & \\
\hline \multirow[t]{18}{*}{ Axis I comorbidity (current [past] No.) } & Major depressive disorder $(0[18])$ & None \\
\hline & Dysthymia (2) & \\
\hline & Panic disorder without agoraphobia (7) & \\
\hline & Panic disorder with agoraphobia (2 [1]) & \\
\hline & Agoraphobia without panic disorder (1) & \\
\hline & Posttraumatic stress disorder (9) & \\
\hline & Social phobia (10) & \\
\hline & General anxiety disorder (3) & \\
\hline & Specific phobia (1) & \\
\hline & Obsessive-compulsive disorder (3 [1]) & \\
\hline & Anorexia nervosa $(0[2])$ & \\
\hline & Bulimia nervosa (2 [4]) & \\
\hline & Binge eating disorder (2) & \\
\hline & Alcohol abuse (0 [2]) & \\
\hline & Cannabinoid abuse $(0[1])$ & \\
\hline & Cocaine dependence $(0[3])$ & \\
\hline & Sedative dependence $(0[1])$ & \\
\hline & Polydrug dependence $(0[1])$ & \\
\hline \multirow[t]{4}{*}{ Axis II comorbidity (No.) } & Avoidant PD (5) & None \\
\hline & Histrionic PD (1) & \\
\hline & Narcissistic PD (1) & \\
\hline & Dependent PD (1) & \\
\hline
\end{tabular}

Abbreviations: BPD = Borderline personality disorder; BSL = Borderline Symptom List; DSS = Dissociative States Scale (state dissociation); FDS = Fragebogen zur Erfassung Dissoziativer Symptome (German adaptation of the Dissociative Experience Scale) (trait dissociation); PD = personality disorder.

* Not statistically significant.

${ }^{\dagger} \mathrm{p}<0.05$ using a 2-tailed t-test. 